LA-UR-99-5181

Approved for public release; distribution is unlimited.

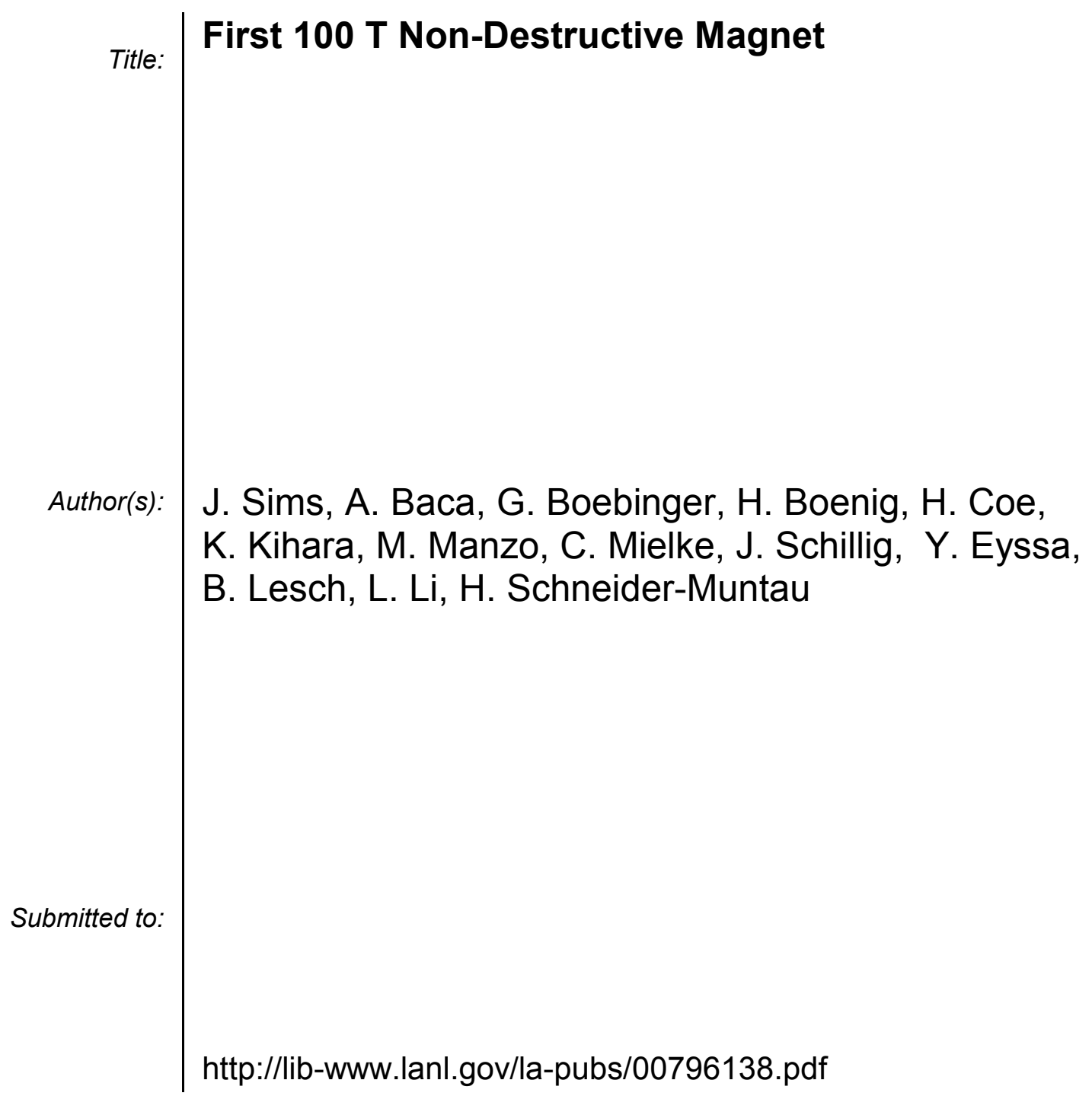

Los Alamos National Laboratory, an affirmative action/equal opportunity employer, is operated by the University of California for the U.S. Department of Energy under contract W-7405-ENG-36. By acceptance of this article, the publisher recognizes that the U.S. Government retains a nonexclusive, royaltyfree license to publish or reproduce the published form of this contribution, or to allow others to do so, for U.S. Government purposes. Los Alamos National Laboratory requests that the publisher identify this article as work performed under the auspices of the U.S. Department of Energy. Los Alamos National Laboratory strongly supports academic freedom and a researcher's right to publish; as an institution, however, the Laboratory does not endorse the viewpoint of a publication or guarantee its technical correctness. 


\title{
First 100 T Non-Destructive Magnet
}

\author{
J. Sims, A. Baca, G. Boebinger, H. Boenig, H. Coe, K. Kihara, M. Manzo, C. Mielke, J. Schillig \\ National High Magnetic Field Laboratory (NHMFL), Los Alamos National Laboratory
}

Los Alamos, NM 87545, USA

\author{
Y. Eyssa, B. Lesch, L. Li, H. Schneider-Muntau \\ NHMFL, 1800 E. Paul Dirac Drive \\ Tallahassee, FL 32306, USA
}

\begin{abstract}
The first $100 \mathrm{~T}$ non-destructive (100 T ND) magnet and power supplies as currently designed are described. This magnet will be installed as part of the user facility research equipment at the National High Magnetic Field Laboratory (NHMFL) Pulsed Field Facility at Los Alamos National Laboratory. The $100 \mathrm{~T}$ ND magnet will provide a $100 \mathrm{~T}$ pulsed field of $5 \mathrm{~ms}$ duration (above $90 \%$ of full field) in a $15 \mathrm{~mm}$ diameter bore once per hour. Magnet operation will be nondestructive. The magnet will consist of a controlled power outer coil set which produces a $47 \mathrm{~T}$ platform field in a $225 \mathrm{~mm}$ diameter bore. Located within the outer coil set will be a $220 \mathrm{~mm}$ outer diameter capacitor powered insert coil. Using inertial energy storage a synchronous motor/generator will provide ac power to a set of seven ac-de converters rated at $64 \mathrm{MW} / 80 \mathrm{MVA}$ each. These converters will energize three independent coil circuits to create $170 \mathrm{MJ}$ of field energy in the outer coil set at the platform field of $47 \mathrm{~T}$. The insert will then be energized to produce the balance of the $100 \mathrm{~T}$ peak field using a $2.3 \mathrm{MJ}, 18 \mathrm{kV}$ (charged to $15 \mathrm{kV}$ ), $14.4 \mathrm{mF}$ capacitor bank controlled with solidstate switches. The magnet will be the first of its kind and the first non-destructive, reusable $100 \mathrm{~T}$ pulsed magnet. The operation of the magnet will be described along with special features of its design and construction.
\end{abstract}

Index Terms—-high field, pulsed magnet, 100 tesla

\section{INTRODUCTION}

The $100 \mathrm{~T}$ non-destructive (100 T ND) magnet now being designed, analyzed and prototyped at the National High Magnetic Field Laboratory (NHMFL) in Los Alamos and Tallahassee will provide a $100 \mathrm{~T}$ pulsed field in a $15 \mathrm{~mm}$ diameter bore. A graph of a simulated typical pulse is shown in Fig. 1. Magnet operation will be non-destructive and reusable. This magnet will increase the available field in its class by $50 \%$ and the available bore size by $50 \%$. The design, fabrication, and routine safe operation of this magnet will entail significant engineering and materials challenges. The magnetic pressure at $100 \mathrm{~T}$ is approximately $4 \mathrm{GPa}$. The magnet will be installed and operated at the NHMFL pulsed magnet facilities at Los Alamos National Laboratory.

The concept of this magnet: a small magnet operated within a larger platform field, was first proposed in 1992 [1]. The rationale for this type of research magnet and the design philosophy and original specifications are given in [2]-[4]. This paper describes the magnet and associated power supply

Manuscript received September 27, 1999.

This work was supported by US Department of Energy, Division of Materials Sciences and the US National Science Foundation through the NHMFL. and outlines special features of its design and construction. Proposed methods of magnet coil conditioning and magnet operation are also described.

\section{MAGNET}

\section{A. Description}

The magnet will consist of an outer coil set energized with controlled power to provide a $47 \mathrm{~T}$ (net at peak) platform field in a $225 \mathrm{~mm}$ bore. This type of controlled power pulsed magnet was pioneered by the University of Amsterdam [5] and extended to higher fields and a larger bore by the NHMFL $60 \mathrm{~T}$ long pulse (LP) magnet [6]. Located within the outer coil set will be a $220 \mathrm{~mm}$ outer diameter capacitor powered insert coil. This insert coil will produce the balance of the field required to reach the total design field of $100 \mathrm{~T}$. The magnet system will be capable of being pulsed once per hour. Insert coil design life is specified at a minimum of 100 full field pulses.

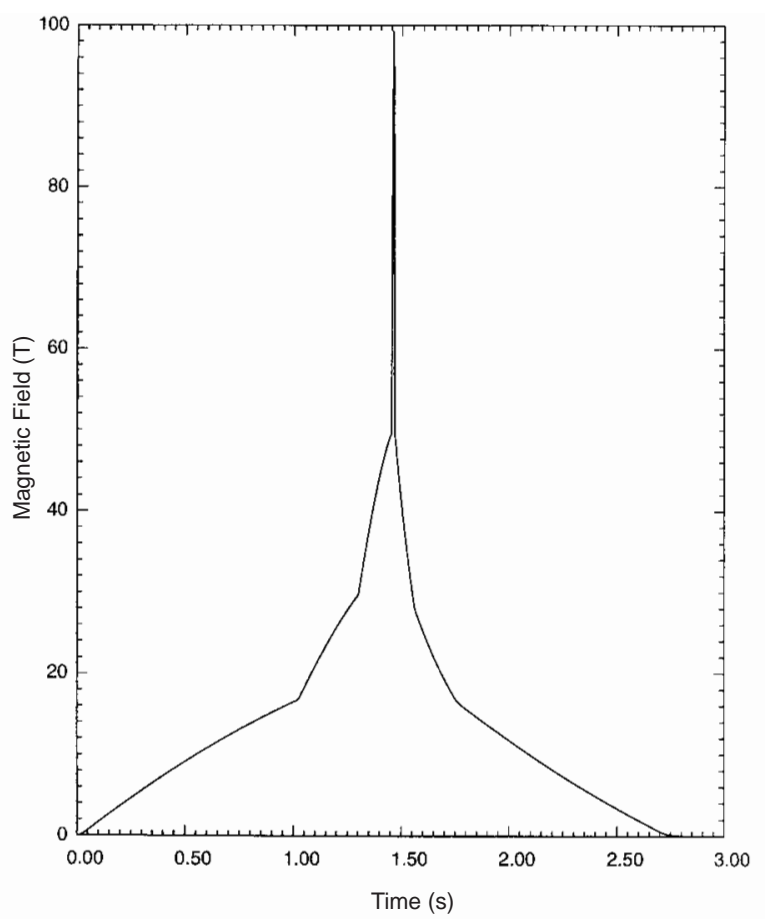

Fig.1. Simulated $100 \mathrm{~T}$ pulse from $100 \mathrm{~T}$ ND magnet. 
The outer coil set design life is specified at 10,000 full field pulses. The ratio of design life between the insert coil and the outer coil set was set by economic and safety requirements. The insert coil will be a less costly and "consumable" component and is designed with design factors that result in higher performance but shorter life. The outer coil set will be expensive and it will contain most of the stored field energy. Therefore, increased design factors with their lower performance were used to attain a predicted long outer coil set life with increased operational safety.

The magnet (Fig. 2) will operate within a stainless steel dewar with a NEMA G-10 fiberglass epoxy laminate lid similar to that used for the $60 \mathrm{~T}$ LP magnet. Many of the $60 \mathrm{~T}$ LP magnet design features are also incorporated into the $100 \mathrm{~T}$ ND outer coil set and dewar design. However, there are several significant design variations or innovations in this new coil set design. These are in the areas of structural support of windings, conditioning or pre-stressing of coil structures, coil lead and busbar design and coil electrical insulation. The insert coil design is an evolution of the internally reinforced coil concept originally developed at the Catholic University in Leuven [7]. Again, the planned 100 T ND insert coil also will incorporate several significant innovations in coil design and materials.

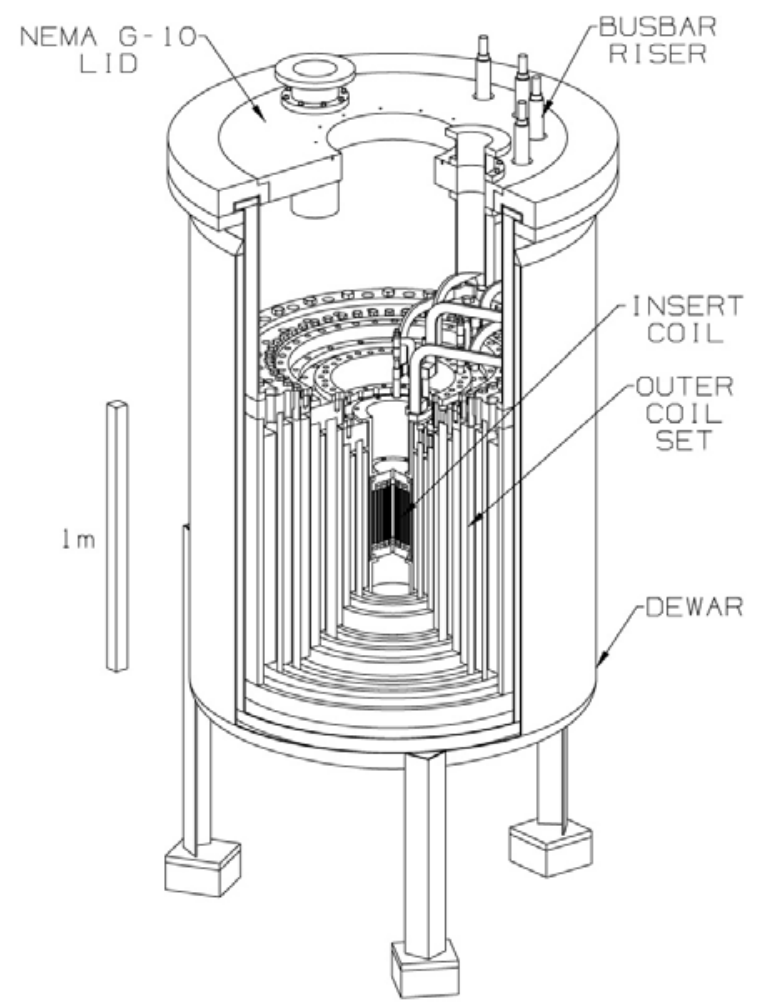

Fig.2. Internal details of $100 \mathrm{~T}$ ND magnet.

\section{B. Insert Coil}

The insert coil will be constructed as a monolithic structure consisting of eight layers wound from $3 \mathrm{~mm} \times 5.8 \mathrm{~mm}$ rectangular conductor. Conductor material will be $\mathrm{CuNb}$ or $\mathrm{CuAg}$ micro-composites or a stainless steel clad copper macrocomposite. Operation of the insert coil immersed in the $47 \mathrm{~T}$ background field will produce the condition of all the insert coil layers being mechanically independent; no mechanical sharing of loads between layers will occur. Each layer of conductor will be supported by appropriately sized reinforcement layers of high modulus (HM) Zylon ${ }^{\mathrm{TM}}$ fiber epoxy composite and MP35 $\mathrm{N}^{\mathrm{TM}}$ (multiphase quaternary alloy: $35 \mathrm{Ni}-35 \mathrm{Co}-20 \mathrm{Cr}-10 \mathrm{Mo}$ ) metal strip.

Noteworthy novel features of the insert coil design will be the internal reinforcement layers of strong and stiff ( $2.7 \mathrm{GPa}$ ultimate tensile strength or UTS and $240 \mathrm{GPa}$ Young's modulus at $77 \mathrm{~K}$ ) MP35N $\mathrm{N}^{\top \mathrm{M}}$ metal alloy strip and the discrete transition rings electrically connecting the coil layers. The insert coil will be mounted within the outer coil set in a manner that permits easy and rapid removal and replacement. Typically, it will not be necessary to warm up the outer coil set to replace the insert coil. Additional information on the insert coil and its materials may be found in [8], [9].

\section{Outer Coil Set}

The outer coil set will consist of seven nested, mechanically independent, freestanding coils each of which are enclosed by a steel reinforcing shell (Fig. 2). The seven coils with their shells will have a mass of approximately $7600 \mathrm{Kg}$.

Coils 1 and 2 incorporate sufficient design flexibility to permit the use of different conductor types. Aluminum oxide dispersion strengthened copper (GlidCop $\mathrm{Al}-60^{\mathrm{TM}}$ ), $\mathrm{CuAg}$ micro-composite or stainless steel clad copper macrocomposite conductor may be used. The final choice of conductor for these coils has not been made but will be determined based on material property qualification tests. Coils 3 through 6 will be wound with GlidCop AL-15 ${ }^{\mathrm{TM}}$ and coil 7, the outermost coil, will be wound with full hard Ag bearing copper (UNS-C10400).

Coils 1 through 4 of the outer coil set will be structurally conditioned using an autofrettage process [5], [10]. Autofrettage will establish a beneficial state of pre-stress in the coil winding and shell by means of an intentional, one time, plastic yielding of coil conductors. This will be achieved by subjecting the coil set to a higher than nominal current pulse. This will effect a permanent state of initial compressive prestress in the coil windings while producing a counterbalancing state of tensile pre-stress in the coil reinforcement. Then, in subsequent nominal pulses operating at lower field and current levels, the coil conductor will experience only elastic strain. Coils 1 through 4 will be supported by very high strength ( 2.5 GPa UTS at $77 \mathrm{~K}$ ) reinforcing shells produced by winding .41 $\mathrm{mm}$ thick, heavily cold worked, stainless steel (UNS-S30100 $\mathrm{XFH}$ ) strip onto Nitronic-40 ${ }^{\mathrm{TM}}$ (nitrogen-alloyed manganese stainless steel: Fe-21Cr-6Ni-9Mn) bobbins. 
The outer coil set will incorporate co-axial coil leads and an adjustable busbar system to reduce magnet assembly time and effort. The outer coil set design will also include additional layers (compared to the $60 \mathrm{~T}$ LP magnet coils) of electrical insulation in the ground wrap of the coils. This will be done to increase the voltage capability between magnet electrical sections. Additional information on the outer coil set, the materials to be used in its construction and the magnet busbar system may be found in other papers to be presented at this conference [9], [11].

\section{POWER SUPPLY}

\section{A. Description}

Using inertial energy storage a synchronous motor/generator will provide ac power to a set of ac-dc converters rated at 64 MW/80 MVA each. These converters energize three independent coil sections of the outer coil set to create $170 \mathrm{MJ}$ of field energy in the outer coil set at the platform field of 47 $\mathrm{T}$. This controlled power system is an upgrade and expansion of the system used to power the $60 \mathrm{~T} \mathrm{LP}$ magnet. The insert coil will be energized using a $2.3 \mathrm{MJ}, 18 \mathrm{kV}$ (charged to 15 $\mathrm{kV}), 14.4 \mathrm{mF}$ capacitor bank controlled with solid-state switches. The outer coil set will require about $390 \mathrm{MW}$ of peak power while ramping up the field and about $300 \mathrm{MW}$ while ramping down. About $235 \mathrm{MJ}$ of energy are needed for the outer coil set to reach peak field. The peak power needed to power the insert coil is about $200 \mathrm{MW}$ and about $1 \mathrm{MJ}$ of energy is needed for the insert to reach peak field. See Fig. 3 for a basic schematic of the power supply.

\section{B. Controlled Power}

The converter based power supply system uses a 1430 MVA energy storage motor/generator set as its energy source and consists of seven $64 \mathrm{MW}$ power supply modules, each providing $4 \mathrm{kV}$ no-load voltage and $3.2 \mathrm{kV}$ full-load voltage at $20 \mathrm{kA}$. The modules are rated to operate at $20 \mathrm{kA}$ for $2 \mathrm{~s}$ once every hour. Presently, five of these seven modules power the 60 T LP magnet; these five power supply modules are connected to form three electrical sections. Two series connected modules power the outer coil sections, two the middle, and one module powers the inner coil sections.

To power the $100 \mathrm{~T}$ ND magnet outer coil set, seven power supply modules will be connected to form three electrical sections. The two modules that now power the outer coil sections of the $60 \mathrm{~T}$ LP magnet will power the inner coil section (coils 1 and 2) of the 100 T ND magnet outer coil set. The two modules that power the middle section of the $60 \mathrm{~T} \mathrm{LP}$ will also power the middle coil section (coils 3 and 4) of the $100 \mathrm{~T}$ ND magnet outer coil set. The single power supply module that powers the inner coils of the $60 \mathrm{~T}$ LP will be connected in series with the two additional modules to power the outer coil section (coils 5, 6 and 7) of the $100 \mathrm{~T}$ ND magnet outer coil set. This approach will achieve the best utilization of the $\mathrm{I}^{2} \mathrm{t}$ rating of the modules.

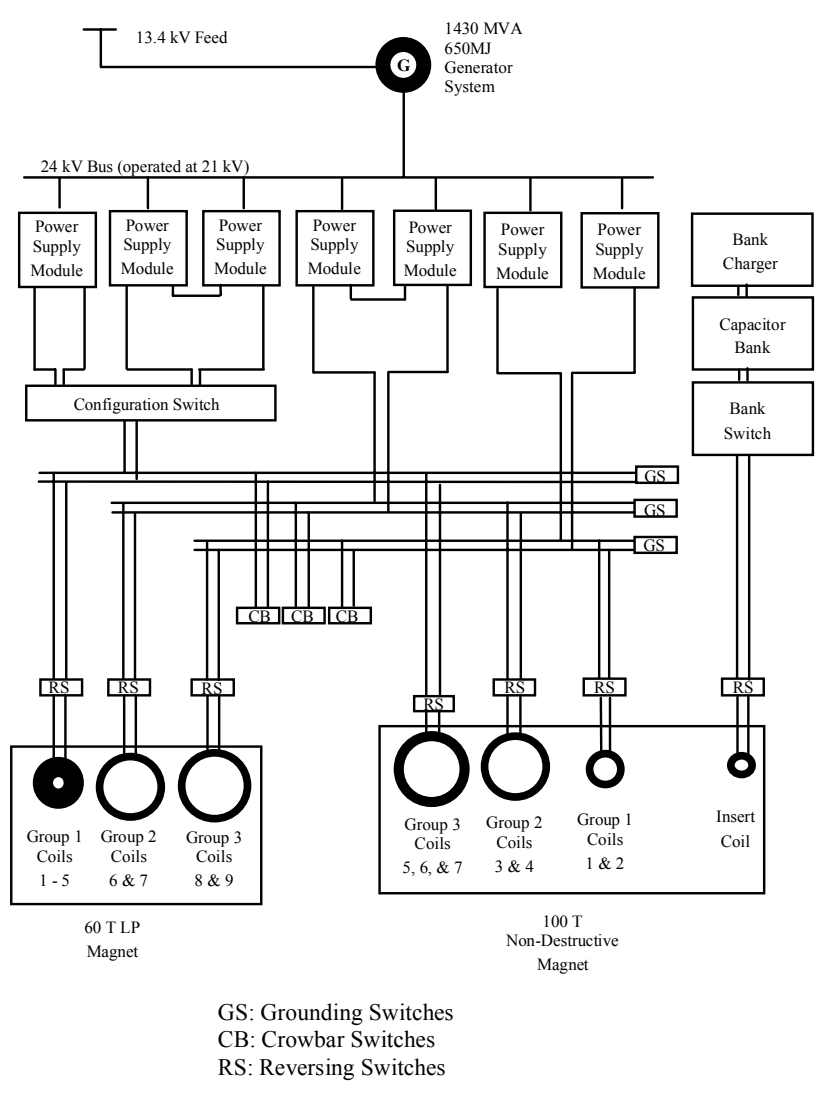

Fig. 3. 60 T LP/100 T ND Power Supply Schematic.

This circuit arrangement will also minimize the number of protection crowbar switches, field reversing switches and the amount of buswork needed. A configuration switch will be required for one of the power supply groups to allow for one or three series module operation as described above. The grounding switches are used to put the system into a safe configuration between pulses. Each magnet (the $60 \mathrm{~T}$ LP and the $100 \mathrm{~T}$ ND) will have its own overcurrent and overheating protection system.

\section{Capacitor Bank}

To accommodate different types of insert designs, the capacitor bank is designed in a flexible way. A total of 48 high energy density, $6 \mathrm{kV}, 52.2 \mathrm{~kJ}$ capacitors have been bought, each with a capacitance of $2.9 \mathrm{mF}$. The design life of the capacitors is 50,000 full voltage charge/discharge cycles with $40 \%$ voltage reversal. It is intended to subdivide the total bank initially into three sections, each section having a voltage of $6 \mathrm{kV}$ and an energy of $835 \mathrm{~kJ}$. The sections will be connected in series for a total output voltage of $18 \mathrm{kV}$.

Each bank section will be connected to a thyristor-closing switch, which controls the discharge of the capacitor section into the magnet. These thyristor switches will consist of a string of three devices in series, with two in parallel, each device having a $4.4 \mathrm{kV}$ voltage rating and a $77 \mathrm{~mm}$ wafer diameter. The switches were designed with an n-1 redundancy, for a total blocking voltage of $12 \mathrm{kV}$. The 
thyristor switch has been tested at $9 \mathrm{kV}$, with a peak current of $73 \mathrm{kA}$ and a sinusoidal pulse length of $7 \mathrm{~ms}$. Each thyristor switch will be protected by an additional inductor, which is connected in series with the switch and the magnet. In the case of a magnet terminal fault, this protection inductor limits the current to about $80 \mathrm{kA}$. The total bank will be charged by two $12.5 \mathrm{kV}, 8 \mathrm{~A}$ charging supplies, which will be thyristor controlled. In general, a constant current charging mode will be used when energizing the capacitor bank. A freewheeling diode stack, with an adjustable resistor in series, will prevent an excessive negative capacitor voltage and heating of the insert coil.

The controls and protection system of the capacitor bank will be tightly integrated into the generator and power converter system control and protection structures. To protect the power supply modules from over voltages in the case of an insert coil pre-firing, fast bi-directional thyristor crowbars will be installed in parallel with the existing mechanical crowbars.

\section{CONDITIONING AND OPERATION}

The $100 \mathrm{~T}$ ND magnet will be operated within a below grade, concrete lined pit. During magnet operation personnel will be evacuated from the building containing the magnet. These measures will be taken to ensure a very high level of personnel safety and to minimize property damage in the event of a magnet failure. A careful procedure of magnet and power supply commissioning will be followed prior to putting the 100 $\mathrm{T}$ ND magnet into routine service. This commissioning will include the higher than nominal pulse to autofrettage or prestress the inner four coils of the outer coil set.

Nominal operation of the magnet will be as follows. The magnet dewar is kept covered to the top of the outer coil set with liquid nitrogen $\left(\mathrm{LN}_{2}\right)$ between pulses. Just prior to a pulse, the $\mathrm{LN}_{2}$ will be drained and only $\mathrm{N}_{2}$ gas at atmospheric pressure will remain in the dewar. The pulse will begin when the outer most section of the outer coil set is energized. Next the middle section of the outer coil set will be energized and then the innermost section of the outer coil set will be energized. When the platform field is attained by the outer coil set, the insert coil will be pulsed by firing the capacitor bank.
Then the peak field of $100 \mathrm{~T}$ will be reached and the field produced by the insert will decay to zero. Next, all three electrical sections of the outer coil set will be actively driven to zero current. When all coil currents attain a zero state the dewar will be re-flooded with $\mathrm{LN}_{2}$ to cool the magnet to $77 \mathrm{~K}$ for the next pulse.

\section{SUMMARY}

A feasible 100-tesla non-destructive magnet system capable of routine operation in support of research has been designed. Detailed design of magnet components is under way. Magnet commissioning is projected to begin in the latter part of 2001 .

\section{REFERENCES}

[1] L. Van Bockstal, P. Pernambuco-Wise, H.-J. Schneider-Muntau, R.J. and L. J. Campbell, "Prospects for a 100 T Long Pulse Magnet," Proceedings of Sixth International Conference on Megagauss Magnetic Field Generation and Related Topics, Albuquerque, New Mexico, November 9-11, 1992, Part I, pp. 59-66.

[2] L. Challis, J. Franse, F. Herlach, and P.Wyder, "European Workshop on Science in 100 T," [KUL, Leuven, Belgium], May 15-17, 1992 (vol. 1); September 30 - October 1, 1994 (vol.2).

[3] G. S. Boebinger, S. Brazovskii, and L. J. Campbell, "Condensed Matter Physics for Non-Destructive 100 T Magnets," Physica B 246-247, 1998, pp. 61-66.

[4] L. J. Campbell, Y. Eyssa, P. Gilmore, P. Pernambuco-Wise, D. M. Parkin, D. G. Rickel, J. B. Schillig, H. J. Schneider-Muntau, "The US 100 T Magnet Project," Physica B 211, 1995, pp. 52-55.

[5] R. Gersdorf, F. A. Muller, and L. W. Roeland, "Design of high field magnet coils for long pulses," Rev. Sci. Instrum. 28, 1965, pp. 949-958.

[6] J. R. Sims, H. J. Boenig, L. J. Campbell, D. G. Rickel, J. D. Rogers, J. B. Schillig, and H. J. Schneider-Muntau, "Completion of the US NHMFL 60 T Quasi-Continuous Magnet," Proceedings of the 15th Intl. Conf. on Magnet Technology, Beijing, China, October 20-24, 1997, pp. 635-641.

[7] L. Van Bockstal, G. Heremans and F. Herlach, "Pulsed Magnetic Fields in the 50-70 tesla Range with Layer by Layer Reinforced Copper Coils", Meas. Sci. Technol., 1991, pp. 1159-1164.

[8] L. Li, et al., "Insert Coil Design of the First 100 T Non-Destructive Magnet," IEEE Transactions on Applied Superconductivity, this issue.

[9] K. Han, et al, "Material Issues in the 100 T Non-Destructive Magnet" IEEE Transactions on Applied Superconductivity, this issue.

[10] R. L. Brockembrough and J. E Steiner, "Autofrettaged Wire-Wrapped Pressure Vessels," ASME Publication Paper No. 76-PVP-47 (1976).

[11] J. L. Bacon, et al., "First 100 T Non-Destructive Magnet Outer Coil Set," IEEE Transactions on Applied Superconductivity, this issue. 